\section{Co-trimoxazole and Typhoid Fever}

SIR,-We definitely agree with Drs. A. M. Geddes and J. A. D. Goodall (26 August, p. 525) that Dr. E. S. Anderson and Mr. H. R. Smith (5 August, p. 329) should have mentioned co-trimoxazole as an alternative drug to chloramphenicol in the treatment of typhoid fever. To date we have successfully treated over 30 patients with acute typhoid or paratyphoid $\mathrm{A}$ fever with this drug. ${ }^{1}$ But in addition we have found co-trimoxazole to be very useful in the treatment of chronic salmonellosis where antibiotic treatment usually has to be given for at least four to six weeks. $^{23}$ In patients with irreparably damaged urinary tracts due to schistosomiasis and persistent salmonella urinary excretion prolonged suppressive therapy with cotrimoxazole has successfully maintained the urine sierile for over a year. ${ }^{4}-$ We are, etc.,

U.S. Naval Medical Research Unit No. 3,

Z. FARID Cairo, Egypt

Abbassia Government Fever Hospital,

A. HASSAN

1 Hassan, A., et al., in preparation.

2 Farid, Z., et al., Fournal of Tropical Medicine and Hygiene, 1970, 73, 153

3 Bassily, S., et al., fournal of Tropical Medicine and Hygiene, 1972, in press.

Bassily, S., Farid, Z., Young, S. W., and
E1-Masry, N. A., Transactions of the Royal Society of
$1972,66,665$.

SIR,-In the article on chloramphenicolresistant Salmonella typhi (5 August, p. 329) we did not mention the use of cotrimoxazole as an alternative to chloramphenicol in the treatment of typhoid fever for a number of reasons. Firstly, though cotrimoxazole appears to induce more rapid symptomatic relief in typhoid I am not yet convinced that its curative efficacy equals that of chloramphenicol, despite the reports quoted by Drs. A. M. Geddes and J. A. D. Goo-iall (26 August, p. 525). (I may add that I do not think that the summation of the findings in a number of independent trials in different countries, including the calculation of a mean case-mortality rate therefrom, is a sound method of assessing the efficacy of a drug. If their own results are considered in isolation Drs. Geddes and Goodall's series of 28 cases with one death showed a casemortality rate of $3.6 \%$, while that in other trials quoted was nil.) In fact, in one of the references cited ${ }^{1}$ the results of treating typhoid in 104 children with co-trimoxazole were compared with those in 40 children treated with chloramphenicol. The authors of this paper state in their summary: "The bacteriological response to trimethoprimsulphamethoxazole was unsatisfactory. From this study it seems that at present chloramphenicol is still the treatment of choice for typhoid fever."

Secondly, the possibility of blood dyscrasias, the main reason for seeking alternatives to chloramphenicol may be no less with co-trimoxazole. Indeed, it may be higher, as Scragg and Rubidge's observations suggest. ${ }^{1}$

Finally, the Mexican epidemic strain of ch'oramphenicol-resistant $S$. typhi, which was the main subject of our article, was also resistant to sulphonamides, including sulphamethoxazole, so that the efficacy of cotrimoxazole in the treatment of infections with this strain would depend on the tri- methoprim component of the mixture. Trimethoprim is not a plausible alternative to chloramphenicol in the treatment of typhoid fever.

I am not condemning the use of cotrimoxazole in typhoid fever, and it may be the best alternative when the infecting strain is resistant to chloramphenicol but not to sulphonamides. I am, however, pleading for caution in the acceptance of co-trimoxazole as a true substitute for chloramphenicol in the treatment of typhoid. Whenever a new drug appears there are optimistic reports of its efficacy in the diseases against which it is aimed, an optimism only too frequently succeeded by disappointment as experience with the drug accumulates. Ampicillin was hailed as an alternative to chloramphenicol in treating typhoid fever, but it has proved disappointing in this respect. Chloramphenicol remains at present the drug of choice for this disease. It is because of this that I am disturbed when strains of $S$. typhi resistant to chloramphenicol appear.-I am, etc.

Enteric Reference Laboratory,

Central Public Healt

Colindale Avenue,

Scragg, J. N., and Rubidge, C. J., British Medical
fournal, 1971, 3, 738.

\section{Evolution of Pathology}

SIR,-I have read with great interest the letters of Professor D. M. Wright (12 August, p. 418) and Dr. E. Elkan (p. 419), with whom I fully agree, commenting on the personal views of Dr. Alec Paton (29 July, p. 287) on the future of histopathology

Pathology has reached an interesting phase in its development marked by the blending of various disciplines of research in the study of fundamental processes and in the reinvestigation of vast morphological fields. Today's research is tomorrow's practice, and many histopathologists would agree that some changes are required in current histopathological practice, upon which much informed surgical opinion relies for diagnostic precision.

The application of electron microscopy is no longer a novelty. The instrument should be, and now usually is, sited in the pathologist's laboratory alongside the other microscopes to be used whenever a resolution better than the optical limit is desired in any problem. Whatever microscope is used, experience is required. As Cappel ${ }^{1}$ reminds us, "There is the microscope, there is the section, there is the pathologist and only his experience to guide him."

Electron microscopy has yielded an immense amount of fundamental information about the structure of cells, tissues, and pathological lesions. In our field it has contributed to a better understanding of the organ of hearing and has provided useful clues in the differential diagnosis of tumours of the head and neck. ${ }^{2}$ The age of miracles in electron microscopy has perhaps passed, though the new types hold out the promise of further advance. We have reached a period of rational hopes based upon intelligent cooperation-a sine qua non as Professor Wright suggests.

If diagnosis is the determination of the cause of disease from symptoms and signs then electron microscopy together with other mew modh may provide considerable diagnostic assistance, reinforcing our observations under the light microscope, which, I hasten to add, will remain a valuable adjunct of electron microscopy.

Gardner ${ }^{3}$ rightly pleaded for "a revolution in diagnostic histopathology." He offered an interesting vista of the future semi-automatic histopathological laboratory. Thank God, and pace Dr. Paton, there will still be room for the pathologist supplying the essential data for the "memory store" and interpreting the oracles emanating from it. "Departments of pathology are the main market for the exchange of knowledge and ideas between those who work in fundamental science and those who work in clinical medicine and surgery."4-I am, etc.,

I. FrIEDMANN

Institute of Laryngology and Otology

1 Cappell, D. F., Lancet, 1960, 2, 863.

2 Friedmann, I., Acta Ótolaryngologica, 1971, 71,

Gardner, D. L., Fournal of Clinical Pathology,
1970, 23, 119. 4 Wright, G. Payling, Lancet, 1963, 2, 1177.

\section{Viral Infection and Asthma}

SIR,-I was interested to read the excellent paper by Dr. H. P. Lambert and Professor H. Stern (5 August, p. 323) on infective factors in exacerbations of bronchitis and asthma. Their findings provide further confirmation of the concept, discussed by Dr. J. E. M. Whitehead (20 May, p. 451), that viral infection causes many more episodes of subclinical than overt illness. As Lambert and Stern point out, this is probably because the outcome of infection is determined not only by properties of the infecting virus but also on constitutional factors in the infected subject. Bronchial hyperreactivity seems to be one such constitutional factor. Five of the 11 exacerbations of asthma in the two asthmatic patients reported by Lambert and Stern were associated with infection by a rhinovirus or parainfluenza virus.

To elucidate the role of constitutional factors in respiratory viral infection a prospective study has been carried out during the past five years in my general practice in collaboration with the Brompton Hospital. Rhinoviruses have been isolated more frequently than any other type of virus in episodes of both upper and lower respiratory illness. The findings in children, in whom rhinoviruses were isolated in 152 episodes, will be fully reported. Rhinoviruses were also isolated in 79 episodes in adults. These findings are analysed in the Table.

In the majority of subjects liable to wheeze rhinoviral infection was associated with an acute onset of wheeze or an exacerbation of chronic wheeze. In seven adults rhinoviruses were isolated in their first known episode of wheeze. Two of them had to be admitted to hospital and three required treatment with corticosteroids or corticotrophin. Six of the seven patients have had further episodes of wheeze, of whom one has required maintenance treatment with prednisone ever since his first episode three years ago and had a severe exacerbation in association with a second rhinoviral infection.

All the rhinoviruses were serotyped by $\mathrm{Dr}$. Mary Roebuck at the Virus Reference 